\title{
Crack Detection in Earth Dams upon a Multiline-Multilaminate Model
}

\author{
Hamzeh Rahimi Dadgar ${ }^{1}$, M.A.Arjomand ${ }^{2 *}$, Ali Arefnia ${ }^{3}$ \\ ${ }^{1}$ Department of Civil Engineering, Roudehen Branch, Islamic Azad University, Roudehen, Iran. \\ E-mail: st.h_rdadgar@riau.ac.ir, a.arefnia@riau.ac.ir \\ ${ }^{2}$ Assistant Professor, Faculty of Civil Eng., Shahid Rajaee Teacher Training University, Tehran, Iran. \\ E-mail: arjomand@sru.ac.ir
}

\begin{abstract}
Earth dams exhibit complex behaviors under various loads and the daily increasing development of the earth dams has made researchers more accurately investigate the soil's mechanical properties including the stress-strain relations and related stress paths. The present study takes advantage of a Multi-Laminate theory to achieve a model that is capable of predicting crack propagation in earth dams on every arbitrary path. The numerical analysis is conducted herein using the finite element method through taking 17 micro scale planes into account. It is by the use of a Multi-Line pattern within the format Multi-Laminate theory for a point in drainage mode that the materials' behaviors have been predicted with a maximum error rate of $13 \%$. It was made clear in this mode that the failure is highly likely to occur on planes 14, 15, 16 and 17 followed by planes 1, 2, 3, 4, 5, 6, 7 and 8that are deemed active, respectively. In normal stress states of the strain, planes $9,10,11,12$ and 13 were also found active besides the abovementioned planes.
\end{abstract}

Keywords:Earth dams, Multiline-Multilaminate Model, Numerical Analysis,,Crack Detection

\section{Introduction:}

Earth dams have relative advantages and are of a particular position in comparison to the other kinds of dams due tohavingbetter behavior in earthquake and other types of loading and taking less cost and time in constructio aspect. They account for a substantial part of the dams constructed around the globe (about 83\%) .Earth dams can exhibit proper behavior against earthquake if they are constructed appropriately but it has to also be noted that a limited number of the large dams have been designed and constructed with the consideration of the effect of strong and/or basic earthquakes. Other factors might come about during earthquake and after that, including the reduction in the masonry's strength and the occurrence of progressive failure that can lead to the destruction and collapse of the earth dams assisted by the redistribution of the pore-water pressure in the dam's body [1]. Pseudo-static is one of the older methods widely used in the designing of the earth-gravel dams for evaluating the stability and performance of the earth-gravel dams in earthquakes [1].

There are studies performed in this regard. Labibzadeh and Sadrnejad used a combination of two theories, named Micro-Plane and Damage theory, in 2007, for constructing a strong but simple behavioral model of the normal concrete.Microplane model was applied to the behavioral model that sought the cracking agent in a combination of the various stresses on 26 micro-plane existent in each Gaussian point. It was figured out that the proposed model predicts the crack occurrence and development stretch in concrete mass under any arbitrary loading combinations with a high precision [2, 3, 4 and 5]. In 2015, another study numerically evaluated the geomechanical characteristics using a multi-laminate structure proposed by Sadrnejad et al.[6]. Jang et al. (2016) dealt with a case study regarding a Concrete Face RockfillDam and the importance of crack detection was also posited therein as a basis for future research [7]. Fisher et al. (2016) investigated the crack and joint progress in clay-core earth dams using numerical modeling [8].

The use of the methods that have acceptable ability in predicting the behavior enables the recognition of all the issues and prevention of all the problems in the analysis of the soil structures. Multi-line analysis can be called one of the first methods in modeling. Elastic patterns by Gauchy and Green, hypoelastic patterns and variable parameter patterns are amongst these. The notable point in these methods is the behavioral modeling in which there is an occasional need for increasing the parameters in an ascending trend for better understanding of the behavior and this might render difficult or even infeasible the determination of the parameters. On the other hand, they feature limited ability in simple forms of stress path. And, this restriction might have caused the researchers to propose more novel models based on more complex mathematical calculations. But, it seems that the primary problem, i.e. dependency on the material type, path and history of stress, still persists at full strength [9]. Therefore, efforts are made to create a process based on a multilinear method within the format of multilaminate model that does not have the abovementioned problems and it can be applied to various conditions including the existence of pore-water pressure and for various constructional materials with different stressstrain history in the numerical static analyses. 


\section{Study Method:}

The present study has been conducted in the form of numerical calculations, laboratory research as well as case study. Numerical modeling will be conducted using multi laminate model and comparison and analysis of the results. A model will be obtained through taking advantage of multi laminate model that is capable of predicting crack propagation in earth dams on any arbitrary stress path. The numerical analysis has been conducted by the use of finite element method and through considering 17 micro-scale planes in such a way that the basics and principles of this multi laminate model and its damage functions will be introduced at first; then, the required parameters are introduced and a method will be expressed for obtaining them. In the end, the input data of the intended earth dam will be extracted subject to the effect of the imposed loads and the constructed model is employed for performing the numerical analysis and the attained results will be investigated and evaluated.

To determine the behavior status of each plane and also for investigating the relationship between the planes' behavior with the total behavior, behavior tensor transfer is used for each of the 17 planes in the general coordinates. The stress and strain vectors for the general coordinate system can be transformed by a transfer matrix into a tri-component vector, including a normal and two shear indicators, and transferred onto each plane.

$$
\begin{aligned}
& \varepsilon_{j}=\left(T_{1}\right)_{j} \varepsilon \text { Equation (1) } \\
& \sigma_{j}=\left(T_{1}\right)_{j} \sigma \text { Equation (2) }
\end{aligned}
$$

$\left(T_{1}\right)_{j}$ denotes the transfer matrix of $\mathrm{j}$-th plane.

$\left(T_{1}\right)_{j}=\left[\begin{array}{cccccc}l^{2} & m^{2} & n^{2} & 2 l m & 2 m n & 2 \ln \\ l l^{\prime} & m m^{\prime} & n n^{\prime} & l m^{\prime}+m l^{\prime} & m n^{\prime}+n m^{\prime} & n l^{\prime}+l n^{\prime} \\ l l^{\prime \prime} & m m^{\prime \prime} & n n^{\prime \prime} & l m^{\prime \prime}+m l^{\prime \prime} & m n^{\prime \prime}+n m^{\prime \prime} & n l^{\prime \prime}+l n^{\prime \prime}\end{array}\right]$

$l, m, n$ Normal vector direction cosines

$l^{\prime}, m^{\prime}, n^{\prime}$ Shear vector (1) direction cosines

$l^{\prime \prime}, m^{\prime \prime}, n^{\prime \prime}$ Shear vector (2) direction cosines

The relationship between stress and strain on each plane can be specified as shown below:

$$
\varepsilon_{j}=C_{j} \sigma_{j} \text { Equation (4) }
$$

Where, $C_{j}$ is the behavior tensor on $\mathrm{j}^{\text {th }}$ plane. This tensor can be determined in a multilinear process for each plane. For $\mathrm{i}^{\text {th }}$ line of the $\mathrm{j}^{\text {th }}$ plane, the multilinear stress-strain relationship can be written as demonstrated below:

$$
\left\{\begin{array}{c}
\varepsilon_{n} \\
\varepsilon_{t 1} \\
\varepsilon_{t 2}
\end{array}\right\}=\left[\begin{array}{ccc}
\frac{1}{\left(G_{1}\right)_{i}} & 0 & 0 \\
0 & \frac{1}{\left(G_{2}\right)_{i}} & 0 \\
0 & 0 & \frac{1}{\left(G_{2}\right)_{i}}
\end{array}\right]\left\{\begin{array}{l}
\sigma_{n} \\
\tau_{1} \\
\tau_{2}
\end{array}\right\}+\{\varepsilon\}_{i-1}
$$

\section{Equation (5)}

$\left(G_{1}\right)_{i}$ is the slope of the $\mathrm{i}^{\text {th }}$ normal stress-normal strain line

$\left(G_{2}\right)_{i}$ is the slope of the $i^{\text {th }}$ shear stress-shear strain line on directions (1) and (2)

$\{\varepsilon\}_{i-1}$ is the strain vector in the end of the $i 1^{\text {th }}$

The following relation is obtained by inserting relation (2) in relation (4):

$$
\varepsilon_{j}=C_{j} \cdot\left(T_{1}\right)_{j} \cdot \sigma \text { Equation (6) }
$$


Considering the fact that the strain is the result of the numerical integration of each plane's strain that is transferred to the general coordinate system, the following relations are written [10\&11]:

$$
\varepsilon=\frac{8 \pi \sum_{j=1}^{17} w_{j}\left(T_{2}\right)_{j} \cdot C_{j} \cdot\left(T_{1}\right)_{j}}{\frac{4 \pi}{3}} \sigma=6 \sum_{j=1}^{17} w_{j}\left(T_{2}\right)_{j} \cdot C_{j} \cdot\left(T_{1}\right)_{j} \sigma
$$

Equation (7)

$w_{j}$ : the weight coefficient of $\mathrm{j}^{\text {th }}$ plane

$\left(T_{2}\right)_{j}$

$j$ : matrix for transferring from $\mathrm{j}$-th plane to the general coordinate system that is defined in the following form based on direction cosines:

$$
\left(T_{2}\right)_{j}=\left[\begin{array}{ccc}
l^{2} & 2 l l^{\prime} & l l^{\prime \prime} \\
m^{2} & 2 m m^{\prime} & m m^{\prime \prime} \\
n^{2} & 2 n n^{\prime} & m n^{\prime \prime} \\
l m & l m^{\prime}+m l^{\prime} & l m^{\prime \prime}+m l^{\prime \prime} \\
m n & m n^{\prime}+n m^{\prime} & m n^{\prime \prime}+n m^{\prime \prime} \\
l n & n l^{\prime}+\ln ^{\prime} & n l^{\prime \prime}+\ln n^{\prime \prime}
\end{array}\right]_{\text {Equation (8) }}
$$

Therefore, the material's behavior tensor is obtained in a general system using numerical integration as shown below:

$$
C=6 \sum_{j=1}^{17} w_{j}\left(T_{2}\right)_{j} \cdot C_{j} \cdot\left(T_{1}\right)_{j}
$$

\section{Equation (9)}

In order to be able to use Multi-Line pattern within the format of Multi-Laminate theory in practical problems, its parameters should be seminally determined. To do so, the behavioral model should be adapted to experimental data. In the present study, use has been made of adapting the behavioral pattern to the results of a standard triaxial experiment for three various confining pressures thereby to apply the model parameters for various confining pressures.

\section{Findings:}

1) Validation of the Behavioral Model's Performance for Static State:

To observe the accuracy of the behavioral pattern's performance for the drained static state, use was made of the results of a standard triaxial test by Guanglia et al. [12].

Table 1: The parameters of lines in Multi-Line pattern

\begin{tabular}{|l|l|l|l|l|l|l|l|l|l|}
\hline \multirow{2}{*}{$\begin{array}{l}\text { Confining } \\
\text { pressure }(\mathrm{kPa})\end{array}$} & \multicolumn{4}{l}{ First line } & \multicolumn{4}{l|}{ Second line } & \multicolumn{2}{l|}{ Third line } \\
\cline { 2 - 11 } & $\varepsilon 1$ & $\mathrm{q}$ & $\varepsilon \mathrm{V}$ & $\varepsilon 1$ & $\mathrm{q}$ & $\varepsilon \mathrm{V}$ & $\varepsilon 1$ & $\mathrm{q}$ & $\varepsilon \mathrm{V}$ \\
\hline 50 & 0.05 & 109 & 0.027 & 0.05 & 100 & 0.0025 & 0.05 & 84 & -0.019 \\
\hline 150 & 0.11 & 156 & 0.0335 & 0.11 & 255 & 0.0525 & 0.11 & 245 & 0.044 \\
\hline 300 & 0.15 & 204 & 0.035 & 0.15 & 377 & 0.065 & 0.15 & 444 & 0.078 \\
\hline
\end{tabular}




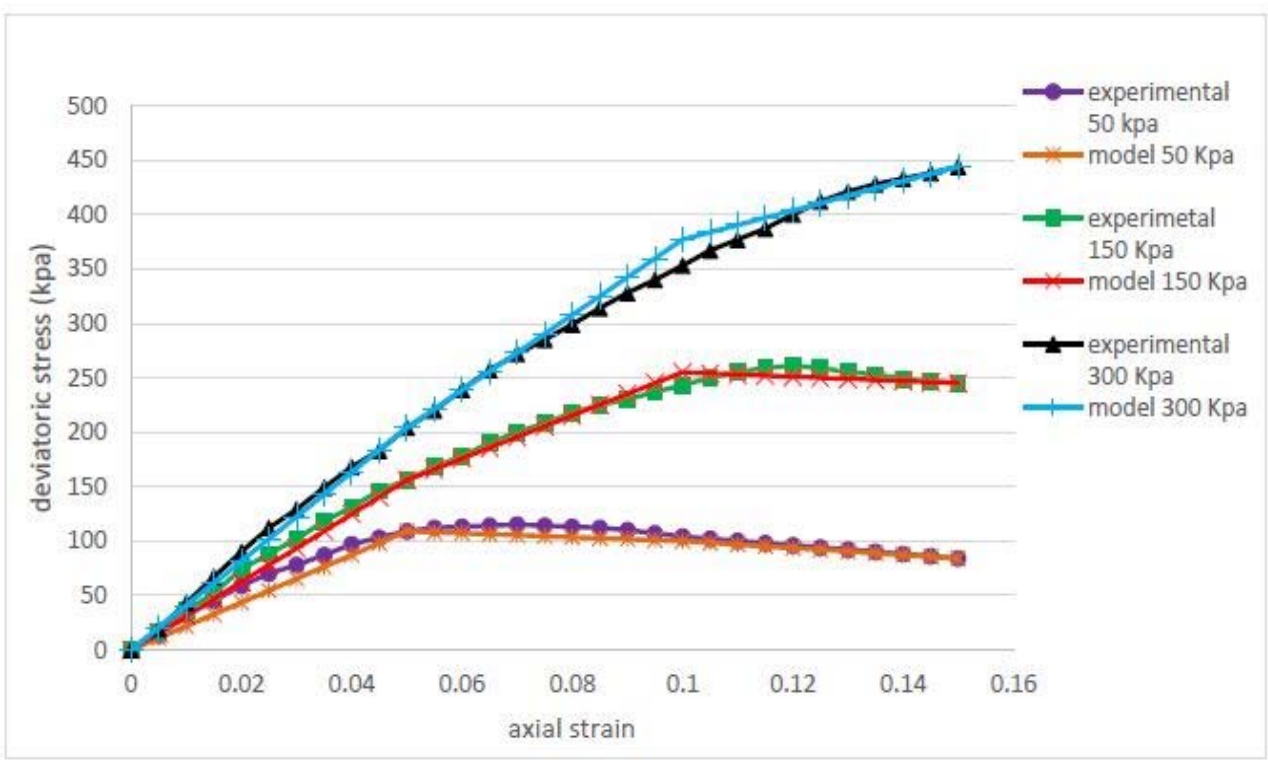

Figure (1): Matching the behavioral model for confining $50 \mathrm{kPa}, 150 \mathrm{kPa}$ and $300 \mathrm{kPa}$ pressures (deviatoric stress-axial strain)

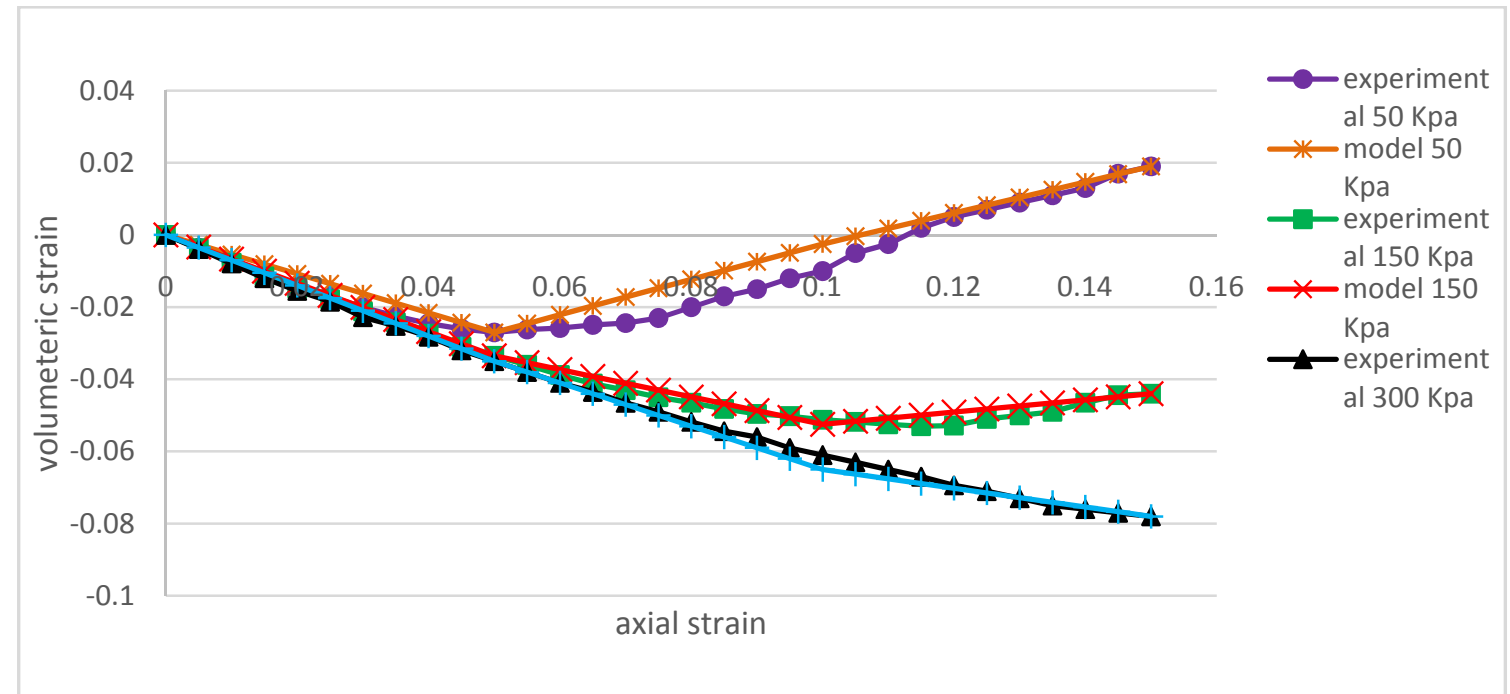

Figure (2): Matching the behavioral model for confining $50 \mathrm{kPa}, 150 \mathrm{kPa}$ and $300 \mathrm{kPa}$ pressures (volumetric strain-axial strain)

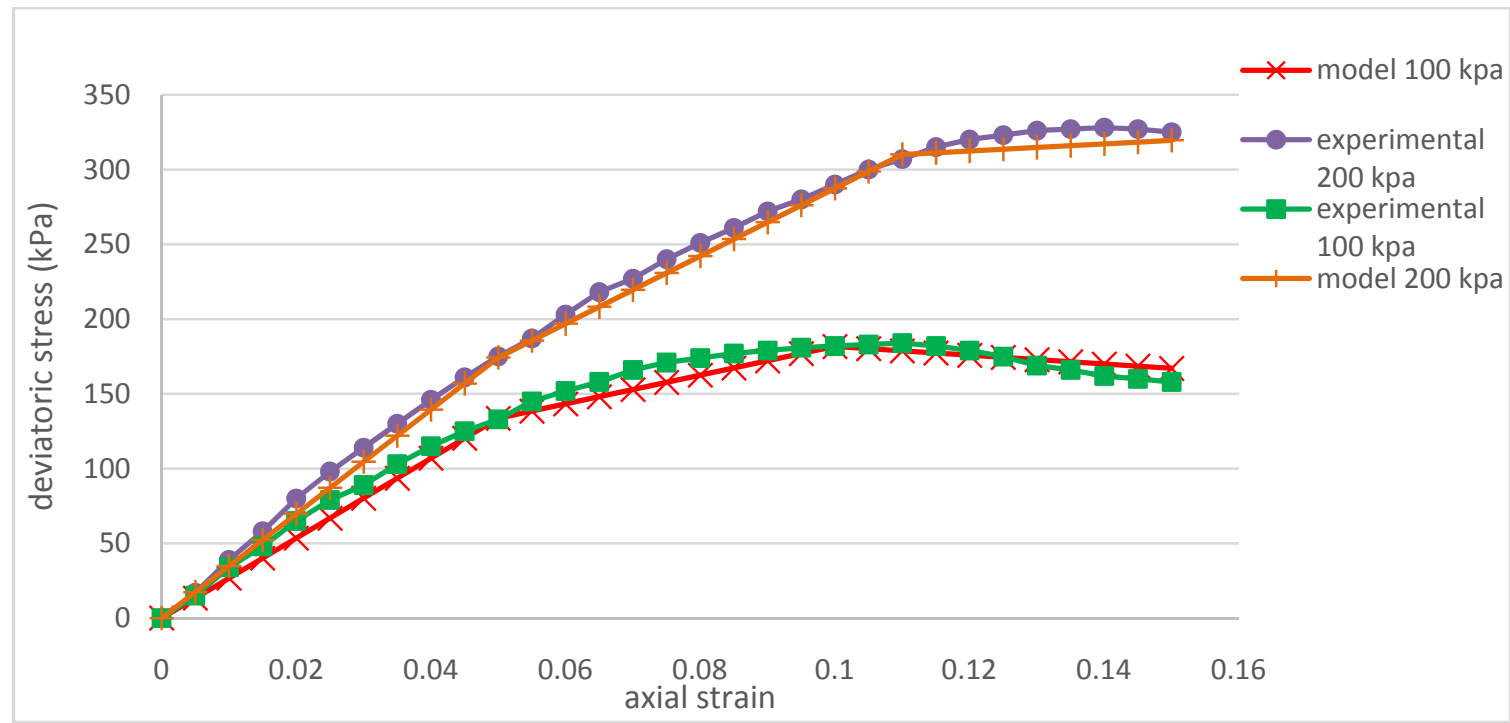

Figure (3): Comparison of the results of the behavioral pattern with the laboratory results for confining $100 \mathrm{kPa}$ and $200 \mathrm{kPa}$ pressures (deviatoric stress-axial strain) 


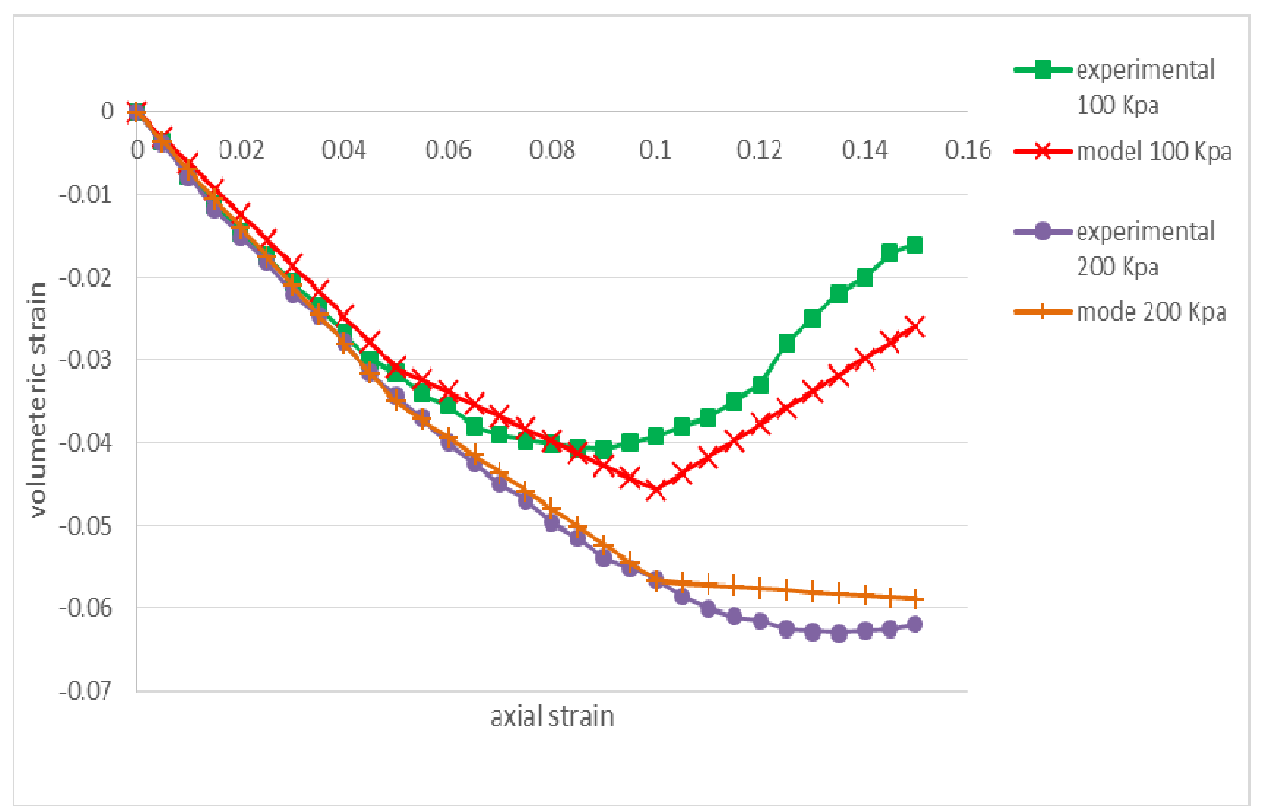

Figure (4): Comparison of the results of the behavioral pattern with the laboratory results for confining 100kPa and 200kPa pressures (volumetric strain-axial strain)

As it is observed in Figures (3) and (4), the structural pattern proposed in the present study gives a good prediction of the materials' behavior and the highest difference between the pattern's prediction and the laboratory results is about $15 \mathrm{kp}$ for deviatoric stress and about 0.08 for volumetric strain both of which are low and acceptable.

Now, the materials' behaviors on the planes are investigated. To do so, the materials' behaviors are examined on the 17 planes for confining $50 \mathrm{kPa}, 100 \mathrm{kPa}$ and $200 \mathrm{kPa}$ pressures. The normal stress-normal strain, output shear stress-output shear strain and shear stress-normal stress curves have been drawn for each of the mentioned confining pressures. The specimen's viscosity is $0.2 \mathrm{kPa}$ and the internal friction angle is 34 degrees.

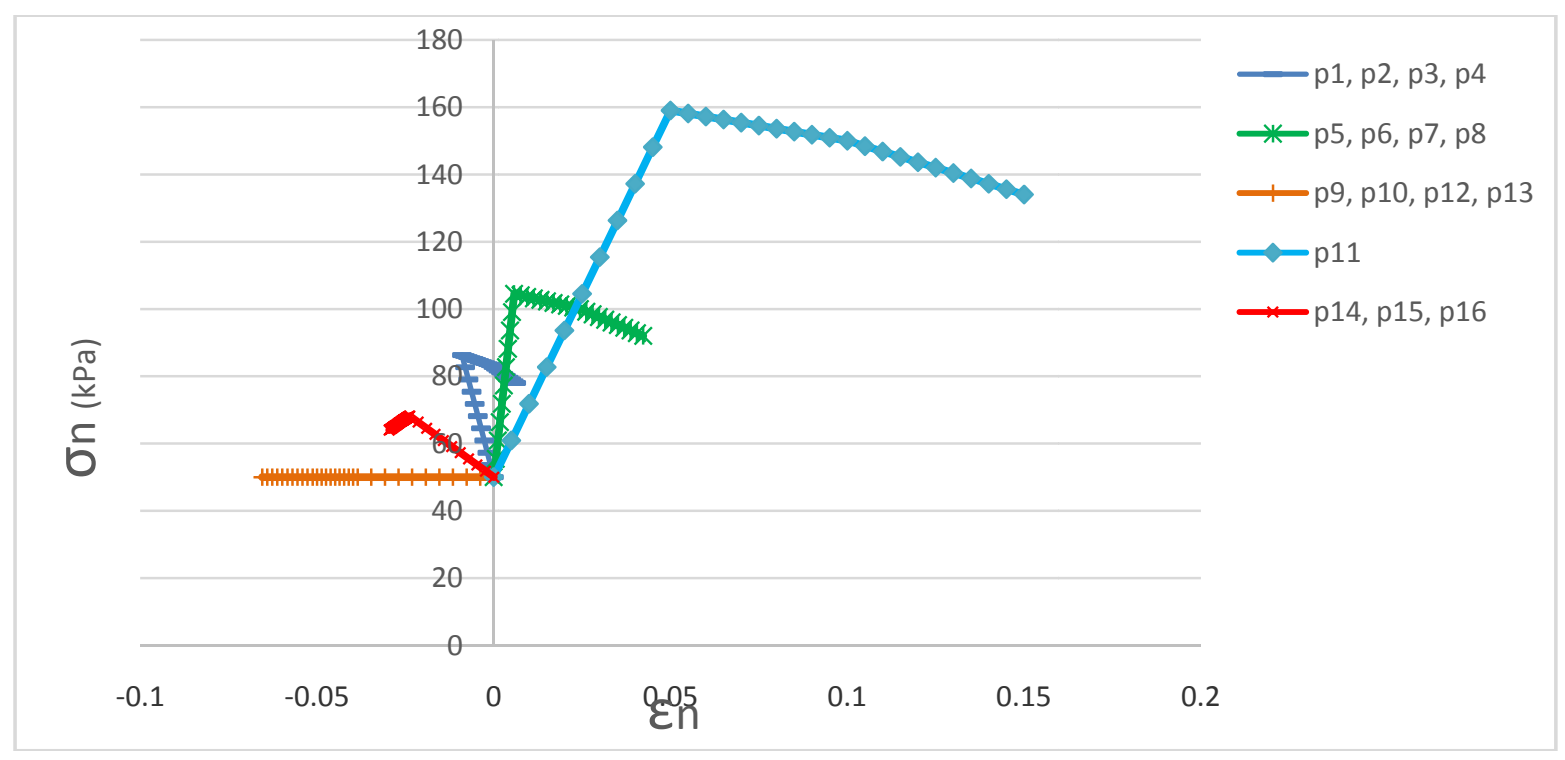

Figure (5): Normal stress-normal strain curves on 17 planes for confining 50kPa pressure 


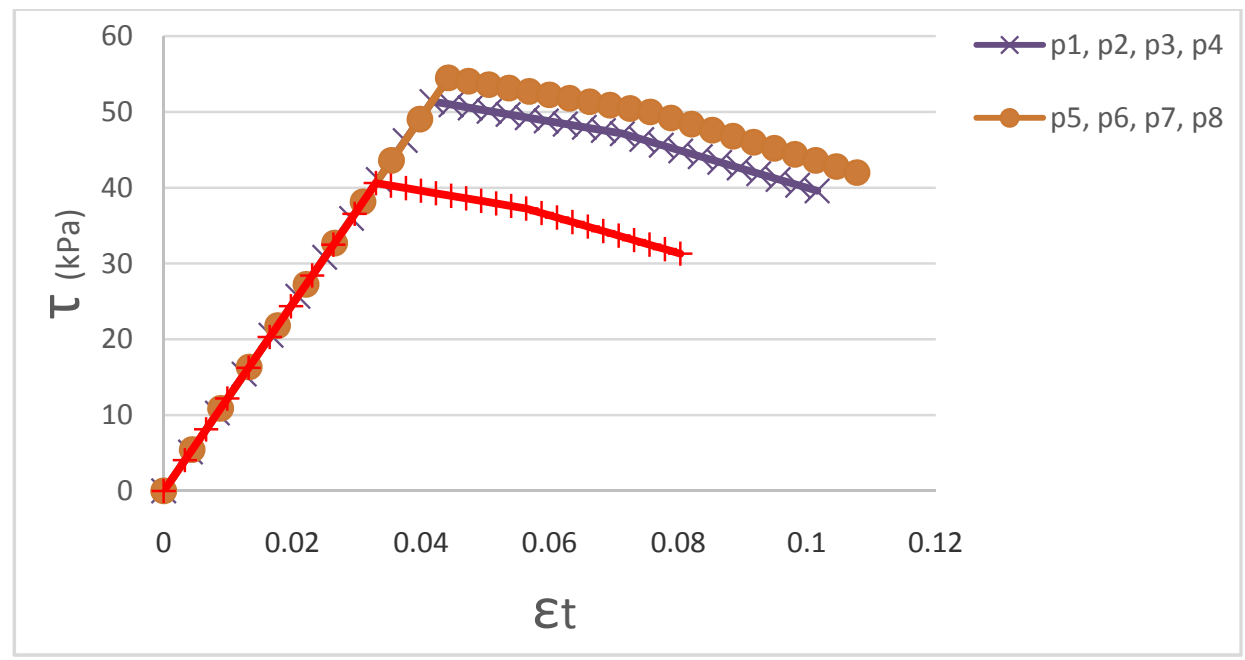

Figure (6): Shear stress-shear strain curves on the 17 planes for confining $50 \mathrm{kPa}$ pressure

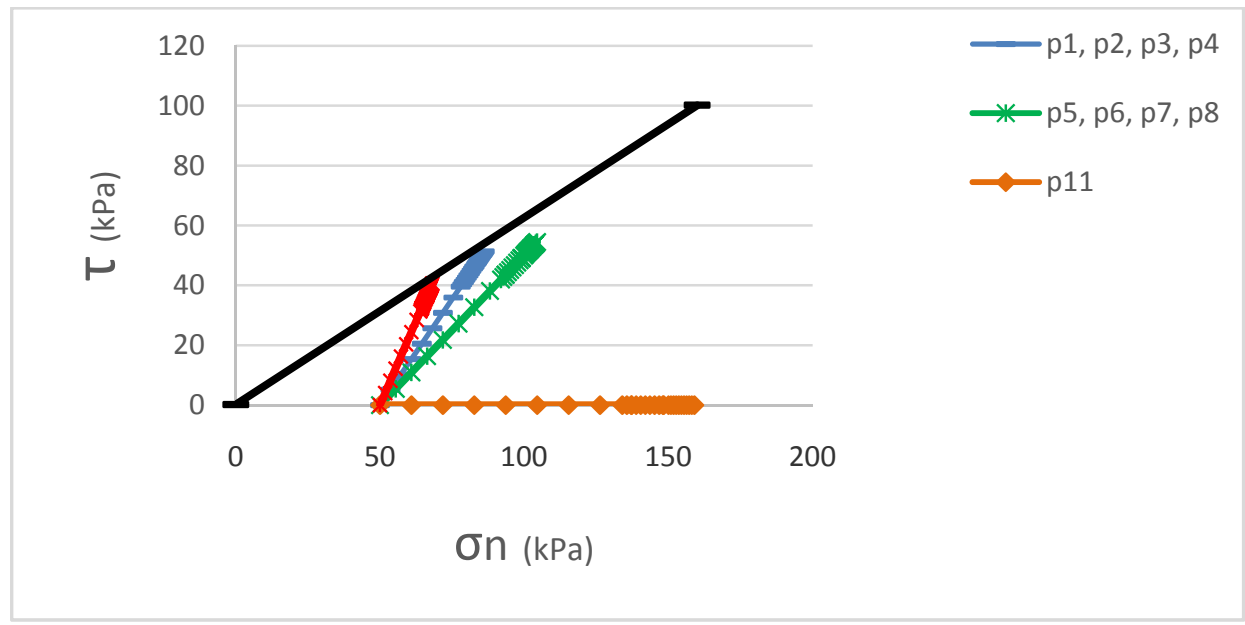

Figure (7): Stress path in normal stress-shear stress space of the 17 planes and comparison with Mohr-Coulomb line for confining $50 \mathrm{kPa}$ pressure

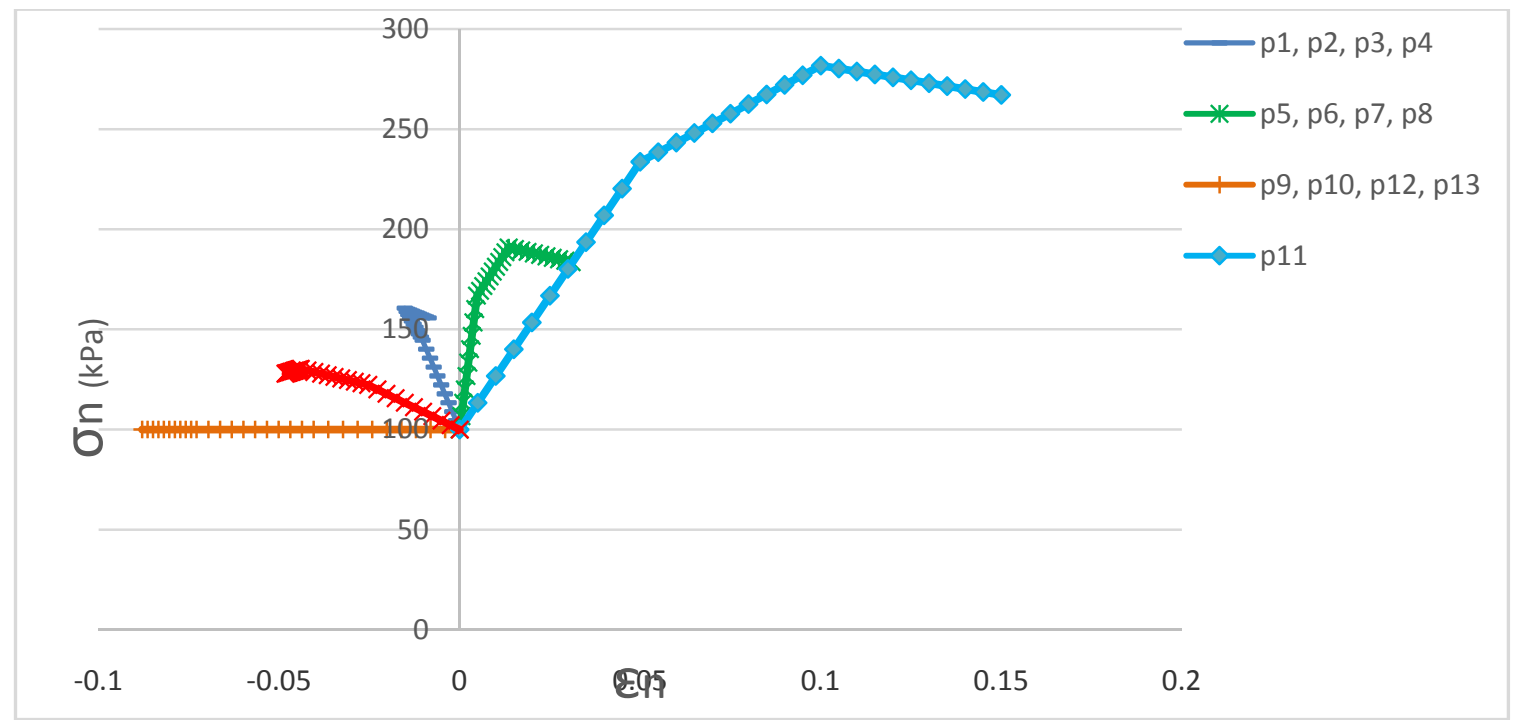

Figure (8): Normal stress-normal strain curves on 17 planes for confining $100 \mathrm{kPa}$ pressure 


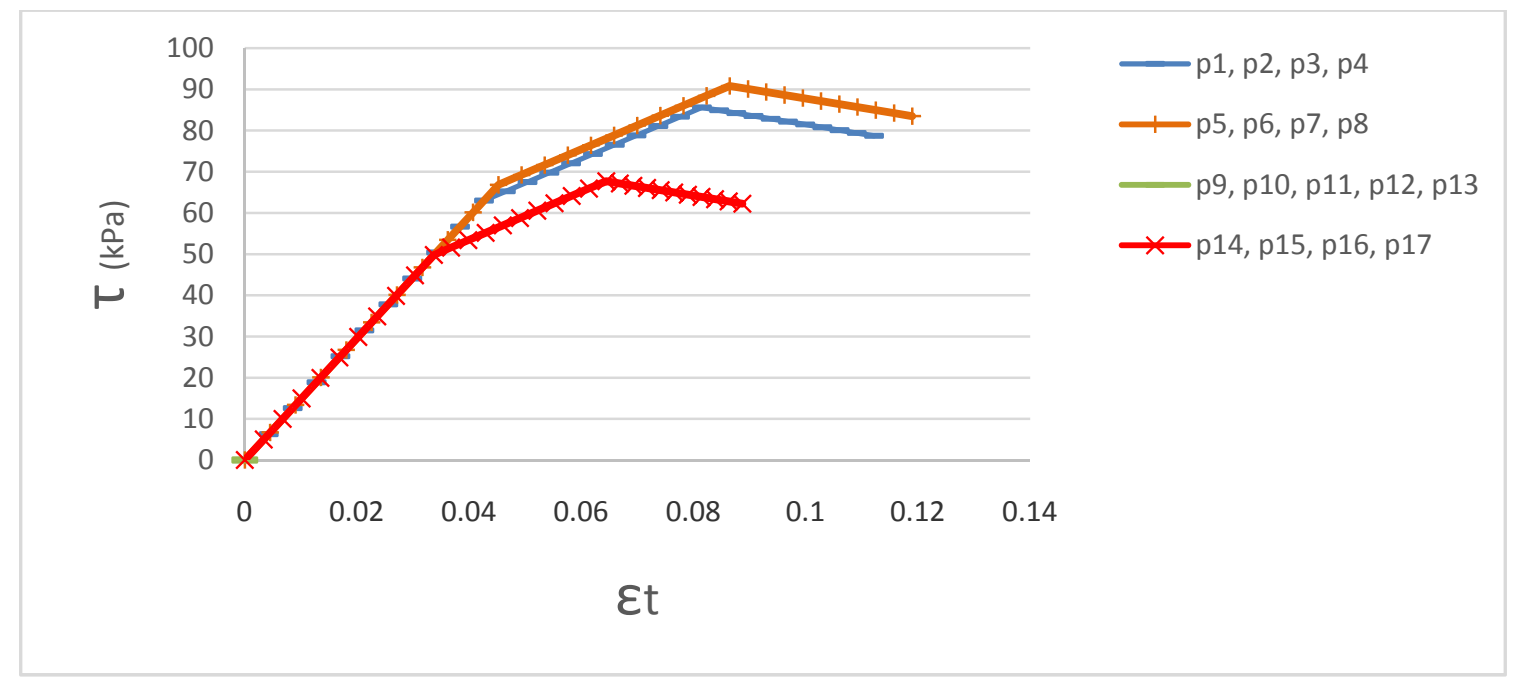

Figure (9): Shear stress-shear strain curves on the 17 planes for confining $100 \mathrm{kPa}$ pressure

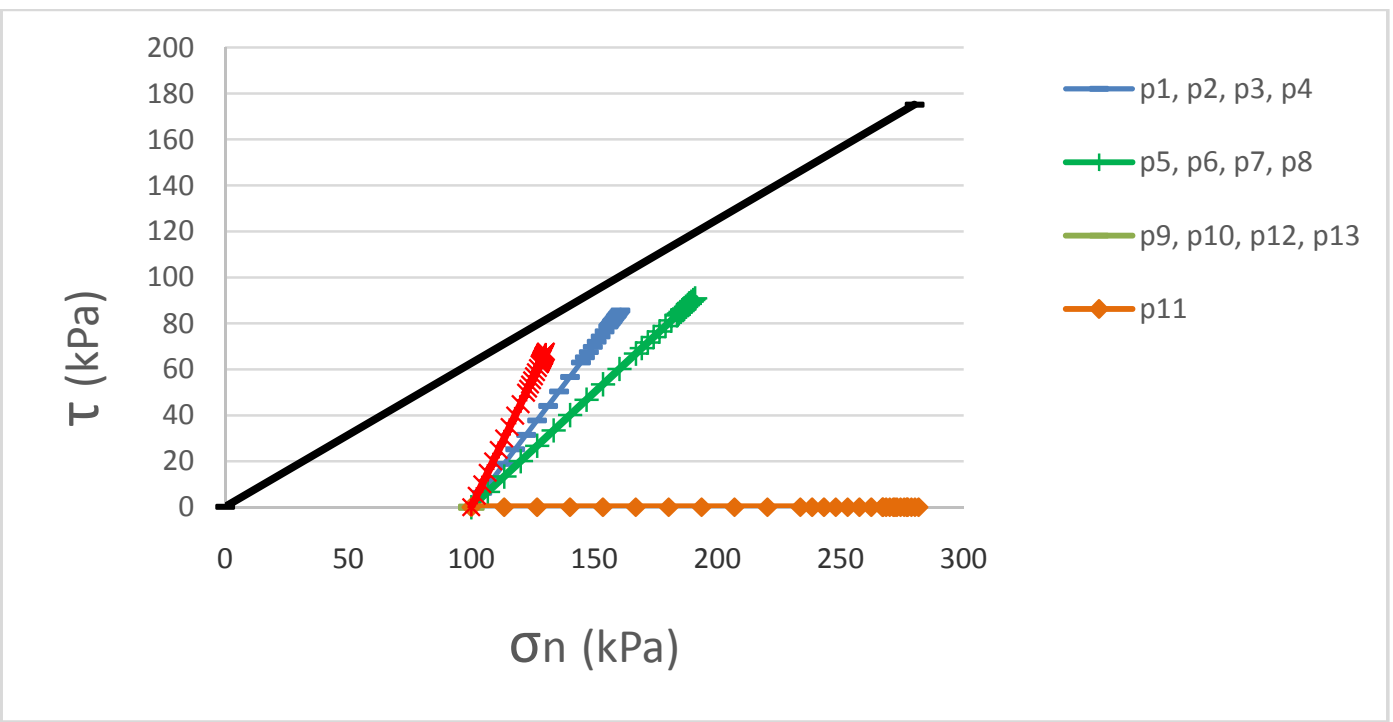

Figure (10): Stress path in normal stress-shear stress space of the 17 planes and comparison with Mohr-Coulomb line for confining $100 \mathrm{kPa}$ pressure

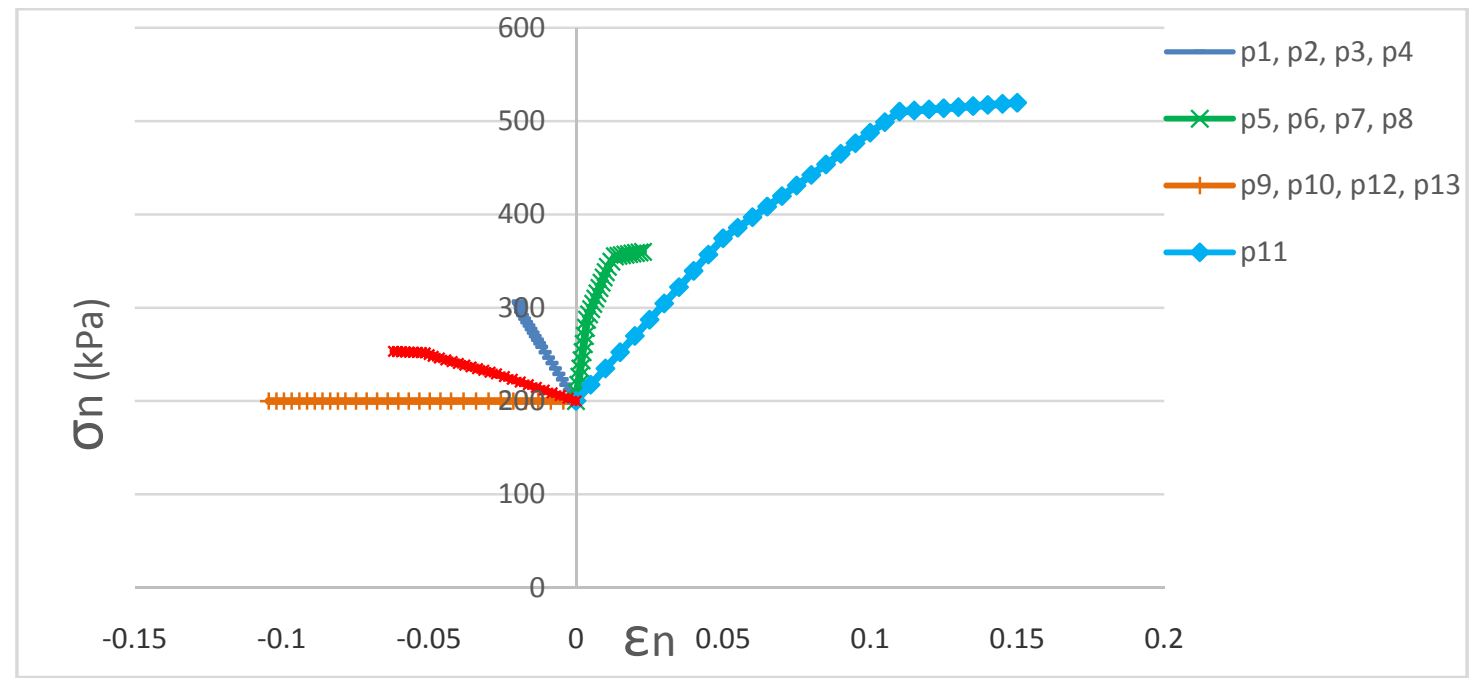

Figure (11): Normal stress-normal strain curves on 17 planes for confining 200kPa pressure 


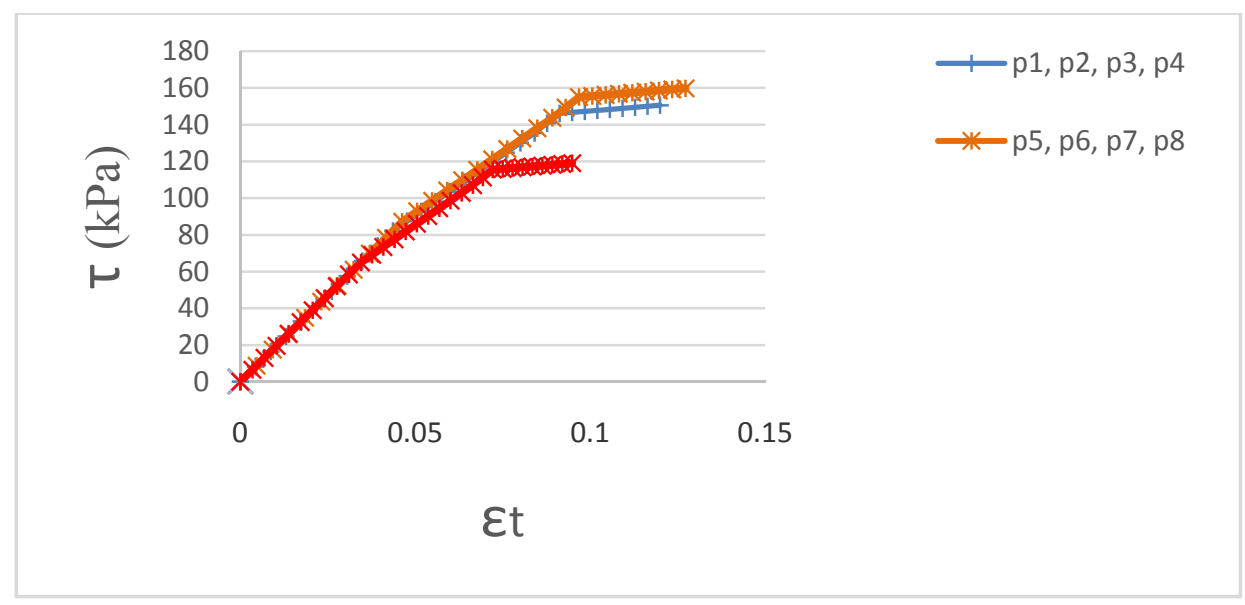

Figure (12): Shear stress-shear strain curves on 17 planes for confining 200kPa pressure

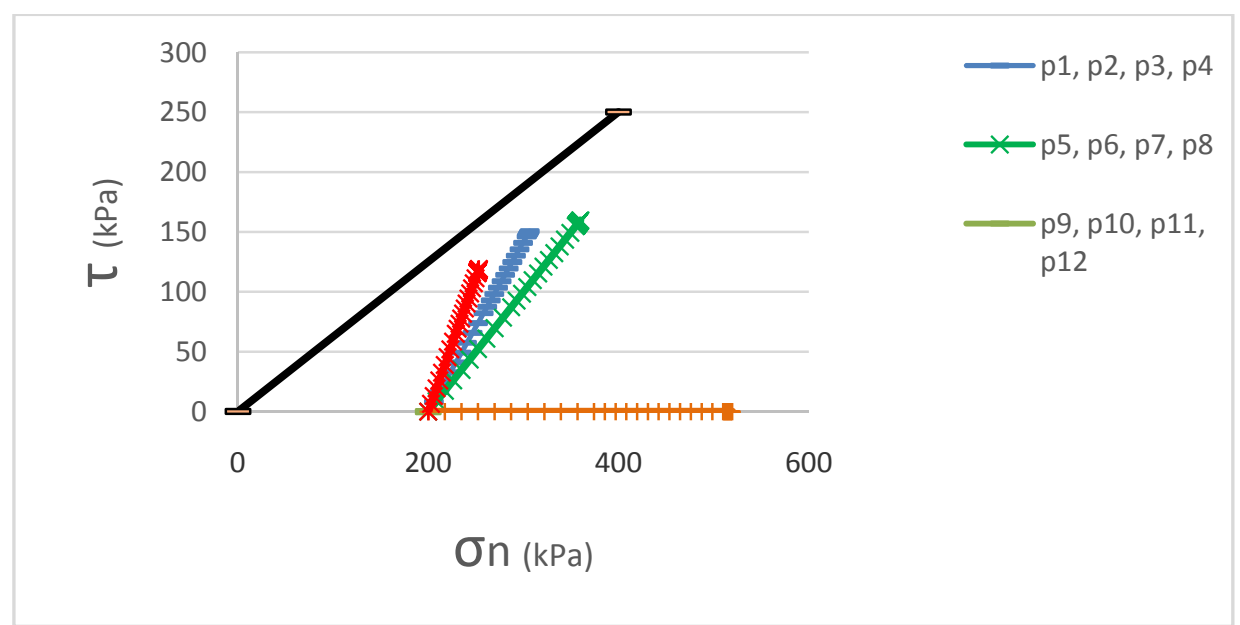

Figure (13): Stress path in normal-stress-shear stress space of the 17 planes and comparison with Mohr-Coulomb line for confining 200kPa pressure

According to the results obtained from Figure (7), it is observed that the stress reaches the Mohr-Coulomb line under confining $50 \mathrm{kPa}$ pressure on planes $14,15,16$ and 17 before the other planes hence the stretch of the contingent failure planes will be as shown in FRigure (13).

2) Validation of the Numerical Software's Performance:

After adding the new model to the OpenSees as a numerical analysis software package, it is necessary to ensure the accuracy of the multiline behavioral model again within the format of multi laminate theory. Thus, to do so, a laboratory standard triaxial experiment was conducted for a pressure rate of $50 \mathrm{KPa}$; the strain-stress and the volumetric strain-axial strain diagrams have been drawn for them with the same elements and the same boundary conditions and stresses as mentioned in [12] following which the behaviors are obtained in the new model in finite element space and compared with the laboratory results. After exerting the confining stresses, the deviatoric stress is imposed and the problem is solved for load control state and the stresses and strains are extracted for element no.17 that is almost in the center of the specimen for static loading mode and the deviatoric stress-axial strain and volumetric strain-axial strain curves are delineated for them and compared with the laboratory results. Figures (14) and (15) illustrate the static loading results. 


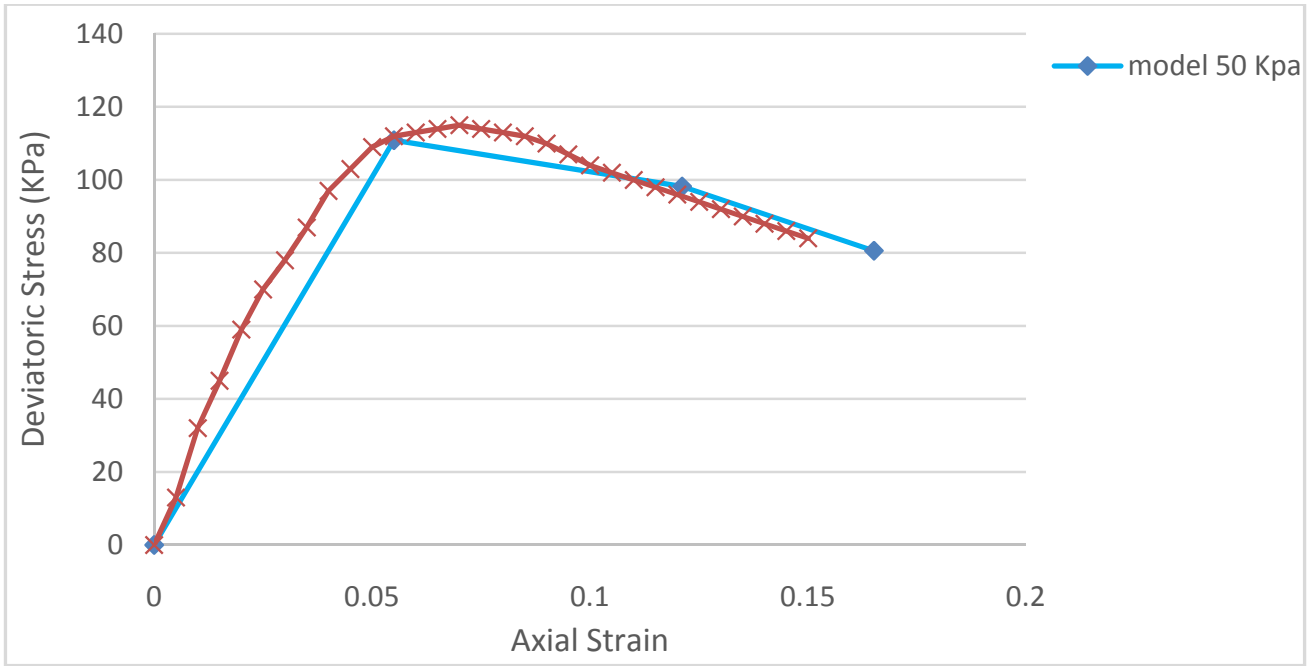

Figure (14): Comparison of the laboratory results of the deviatoric stress-axial strain with the results obtained from numerical software using multiline behavioral model within the format of multi laminate theory

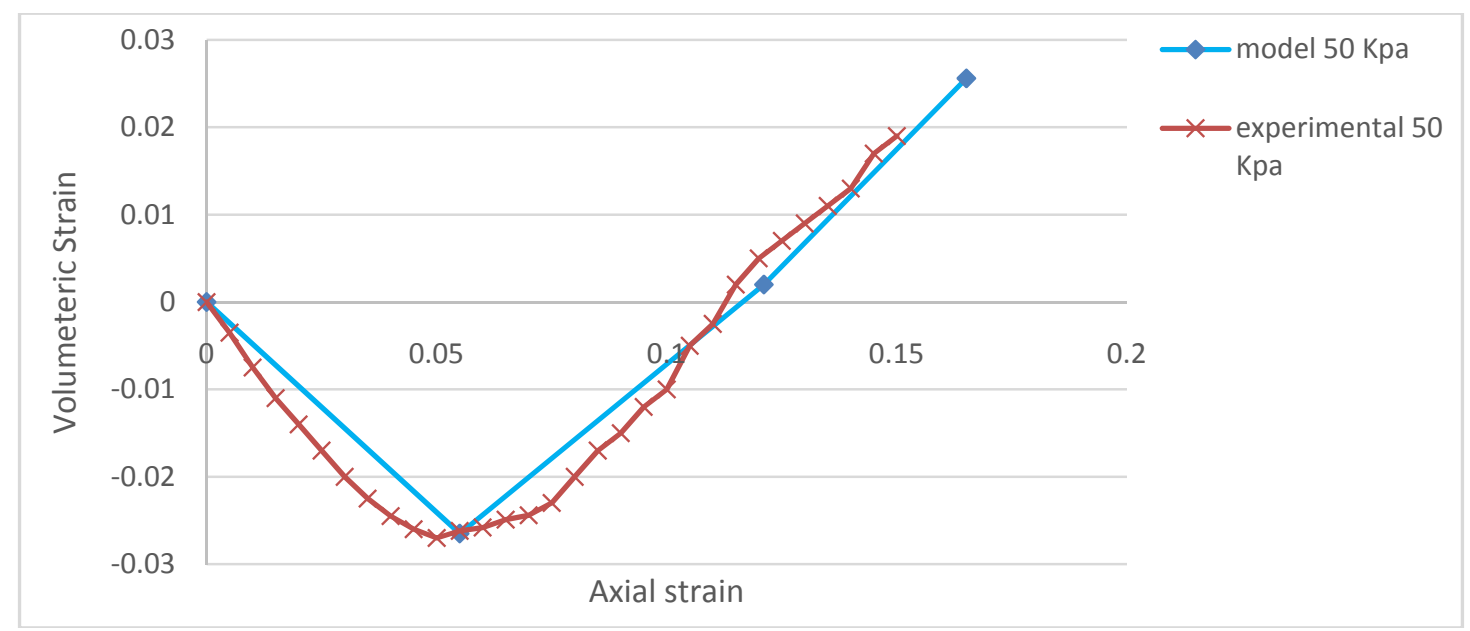

Figure (15): Comparison of the laboratory results of the volumetric strain-axial strain with the results obtained from numerical software using multiline behavioral model within the format of multi laminate theory

The stresses and strains obtained from the numerical software for the aforementioned element were transferred to the 17 planes and the results have been displayed in Figures (16), (17) and (18).

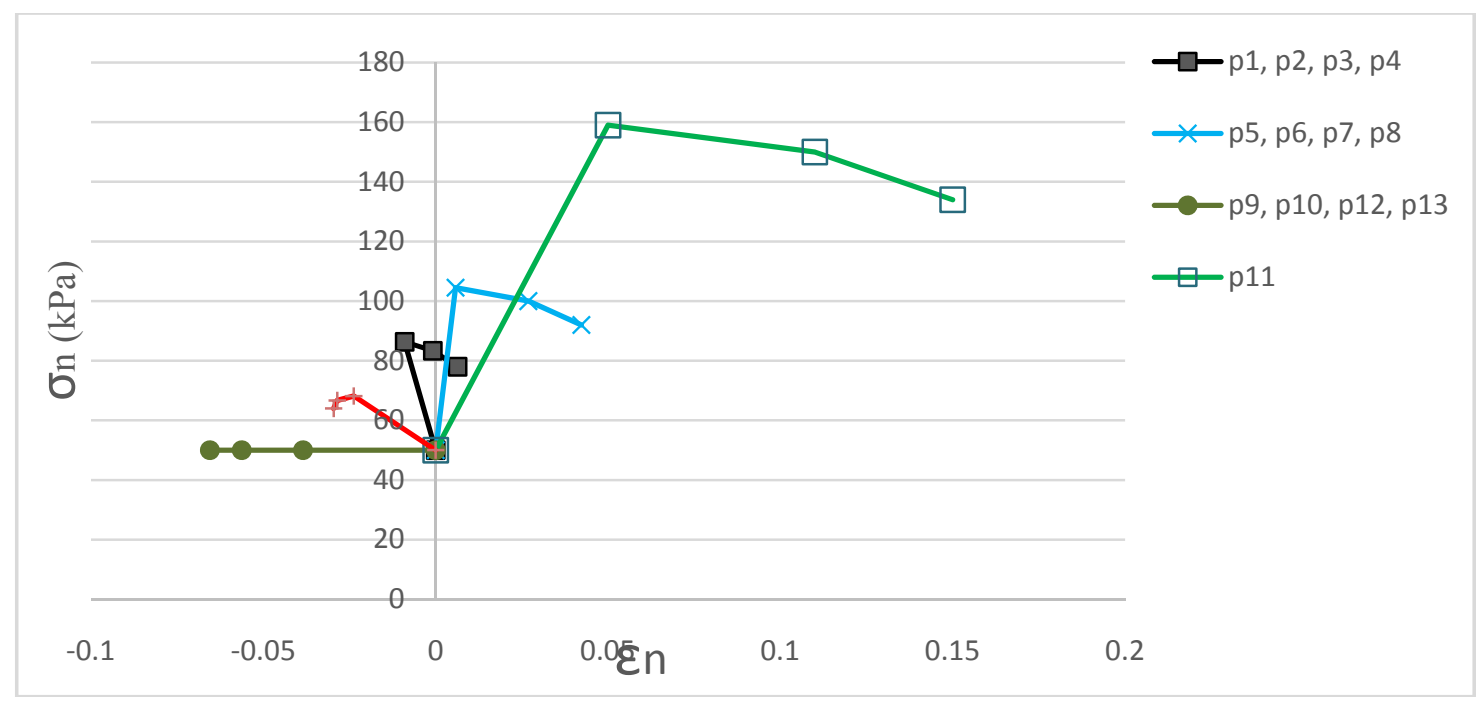

Figure (16): Normal stress-normal strain curves for the 17 planes 


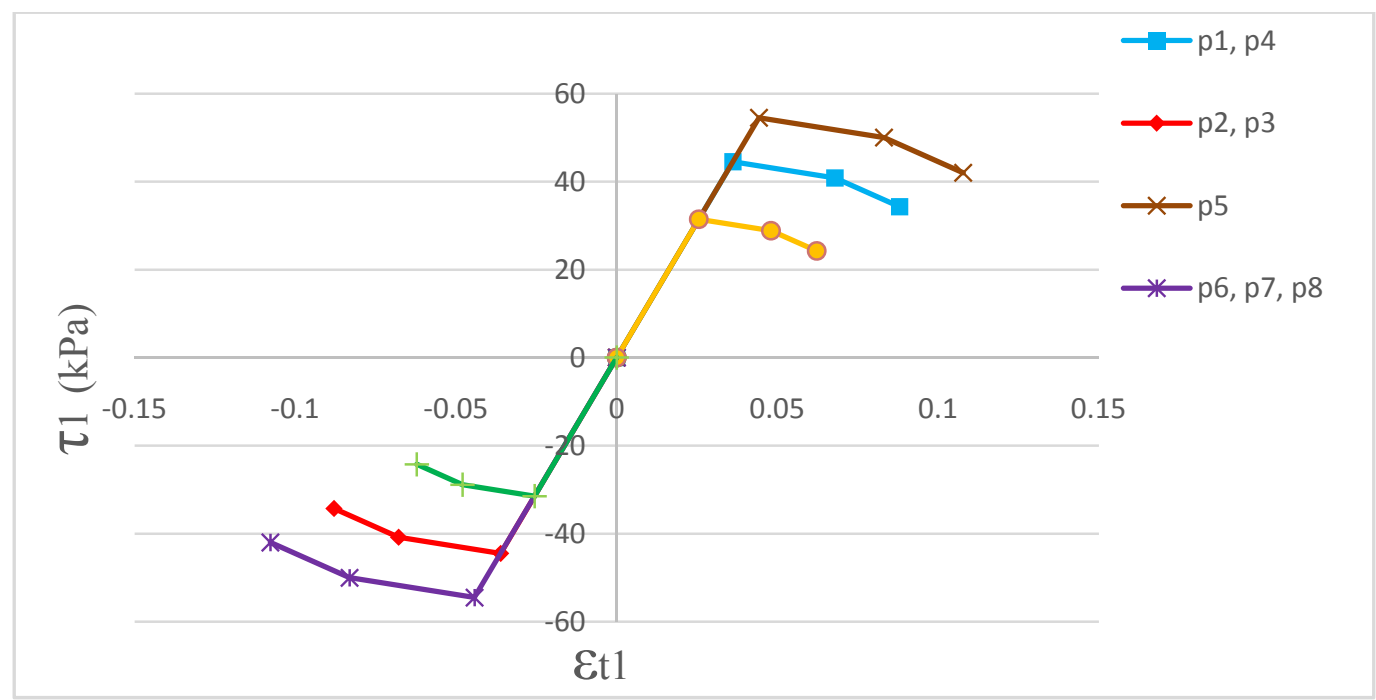

Figure (17): Shear stress-shear strain curves of the first direction for the 17 planes

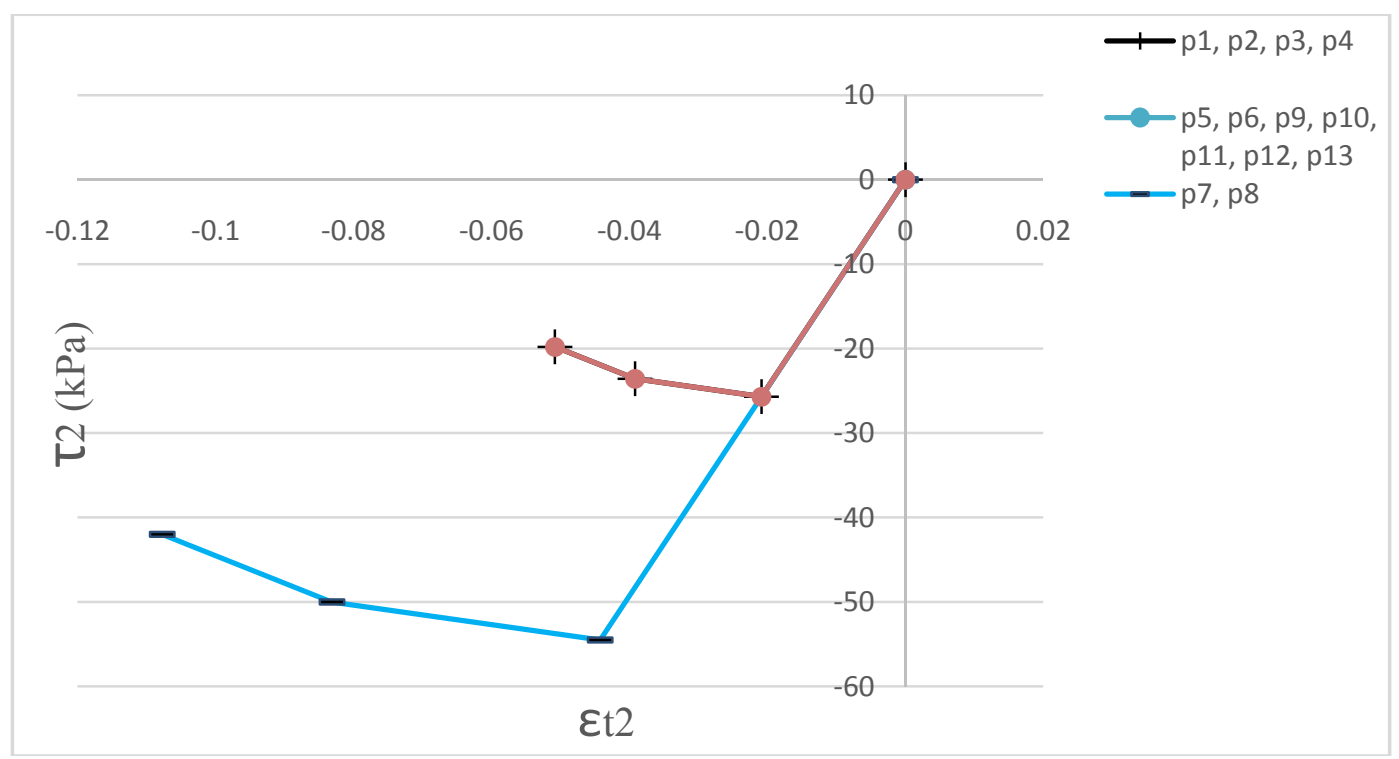

Figure (18): Shear stress-shear strain curves of the second direction for the 17 planes

Now, the stress path is delineated for the same element in normal-stress-output shear stress space for the 17 planes and the shear stress values are compared with Mohr-Coulomb line and the results have been shown in Figure (19). The soil's internal friction angle is 32 degrees and its adhesion is $0.2 \mathrm{kPa}$.

As it is seen in Figure (19), the shear stresses of the planes 14, 15, 16 and 17 are closer to Mohr-Coulomb line and these planes undergo failure earlier. 


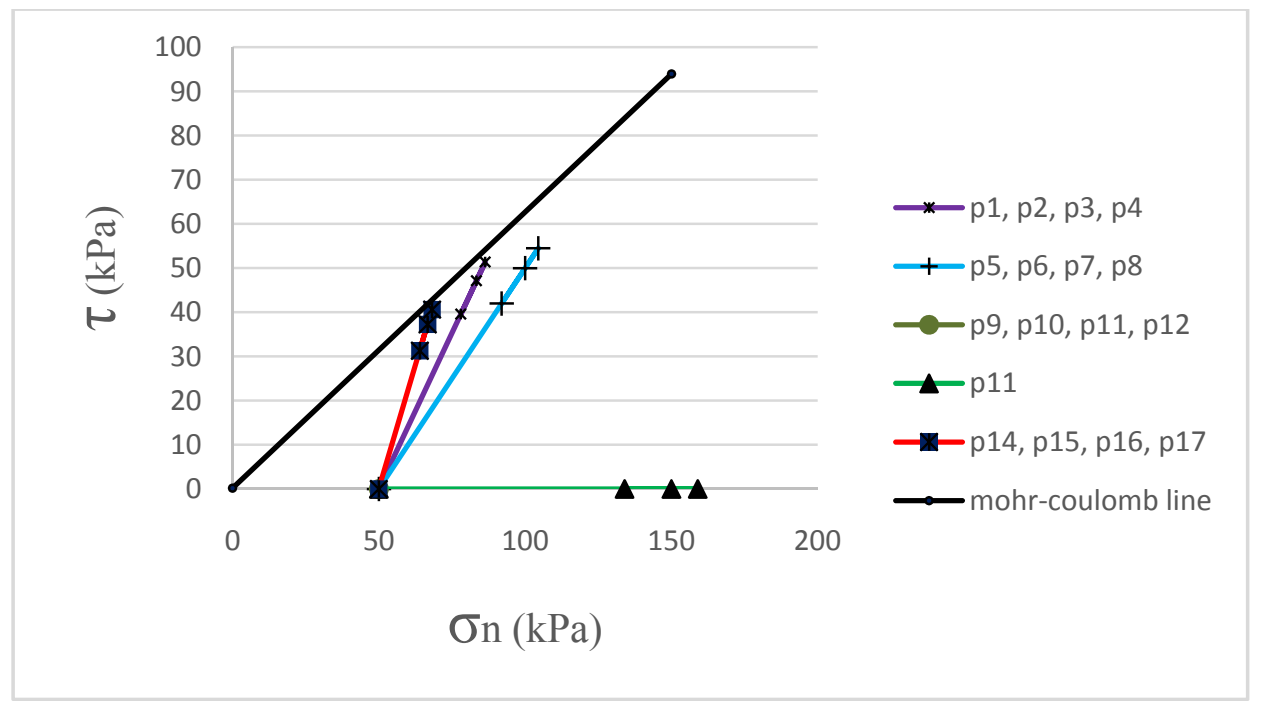

Figure (19): Stress path in normal strain-shear strain path for the 17 planes and comparison with Mohr-Coulomb line

\section{Conclusion:}

- The behavior of the materials has been predicted using a multilaminate-multiline model in a single point for drained state with a maximum error rate of $13 \%$. It was made clear in this state that the planes $14,15,16$ and 17 followed by planes 1, 2, 3, 4, 5, 6, 7 and 8 are most likely to fail, respectively.

- The material's behavior has been predicted using a multiline-multilaminate model for a single point in nondrained state with a maximum error rate of $19 \%$. It was made clear in this state that the failure is highly likely to occur along the planes 14, 15, 16 and 17 followed by active planes 1, 2, 3, 4, 5, 6, 7 and 8; besides the abovementioned planes, the planes $9,10,11,12$ and 13 are also active in normal stress state.

- After adding the behavioral pattern to the numerical analysis software, the results of the same standard triaxial experiment that had been predicted for the single-point state by the model were again predicted by the software and a maximum $17 \%$ error was observed; the results were found completely matching with the single-point model in terms of the failure mechanism and planes' activities.

\section{References:}

[1] Guidelines of the seismic analysis and designing of earth-gravel dams, planning and budget vice chancellor of the presidency, 2013.

[2] Sadrnejad, S., A multi-lined behavior simulationapproach for liquefaction of earth-dam. Computational Methods in Civil Engineering, 2011. 2(2): p. 201-218

[3] Sadrnejad, A., (2011), "plastic limit of soil theory and modeling".

[4] Desai, C.S. and H.J. Siriwardane, Constitutive laws for engineering materials with emphasis on geologic materials. 1984: PrenticeHall.

[5] Naylor, D., Stresses in nearly incompressible materials by finite elements with application to the calculation of excess pore pressures. international journal for numerical methods in engineering, 1974.8 :(3)p. 443-460.

[6] Zienkiewicz, O. and D. Naylor, The adaptation of critical state soil mechanics theory for use in finite elements. Stress-Strain Behavior of Soik, 1972: p. 537-543.

[7] Gu, C., et al., Undrained cyclic triaxial behavior of saturated clays under variable confining pressure. Soil Dynamics and Earthquake Engineering, 2012. 40: p. 118-128.

[8] Sadrnezhad, S., Constitutive model for multi-laminate induced anisotropic double hardening elastic-plasticity of sand. INTERNATIONAL JOURNAL OF ENGINEERING TRANSACTIONS A, 2002. 15: p. 115-124.

[9] Nowzari, A., (2002), "offering a multilinear model of earth materials' behavioral analysis within the format of multiplane model", Khajehh Nasir Al-Din Tusi.

[10] Bažant, Z.P., Y. Xiang, and P.C. Prat, Microplane model for concrete. I: stress-strain boundaries and finite strain. Journal of Engineering Mechanics, 1996. 122(3): p. 245-254.

[11] Ožbolt, J. and Z.P. Bažant, Microplane model for cyclic triaxial behavior of concrete. Journal of engineering mechanics, 1 :(7)118 .992 p. 1987-2007.

[12] Liu, G., et al., Numerical simulation on undrained triaxial behavior of saturated soil by a fluid coupled-DEM model. Engineering Geology, 2015. 193: p. 256-266. 